\title{
Soil-plant interactions and sustainability of eco-agriculture in arid region: a crucially important topic to address
}

\author{
Yongchao Liang • Yong-Guan Zhu • \\ F. Andrew Smith • Hans Lambers
}

Received: 13 October 2009 / Accepted: 16 October 2009 /Published online: 10 November 2009

(C) Springer Science + Business Media B.V. 2009

Keywords Arid region · Microbe $\cdot$ Plant $\cdot$ Soil

China and Australia are both listed among the largest countries in the world. However, China's population

Responsible Editor: Hans Lambers.

Y. Liang $(\bowtie)$

Key Laboratory of Oasis Eco-Agriculture, College of Agriculture, Shihezi University, Shihezi 832003, People's Republic of China e-mail: ycliang@caas.ac.cn

\section{Y. Liang}

Ministry of Agriculture Key Laboratory of Crop Nutrition and Fertilization, Institute of Agricultural

Resources and Regional Planning,

Chinese Academy of Agricultural Sciences,

Beijing 100081, People's Republic of China

Y.-G. Zhu

Research Center for Eco-environmental Sciences,

Chinese Academy of Sciences,

Beijing 100085, People's Republic of China

F. Andrew Smith

School of Earth and Environmental Sciences, University of Adelaide,

Adelaide, South Australia 5005, Australia

H. Lambers

School of Plant Biology,

Faculty of Natural and Agricultural Sciences,

The University of Western Australia,

35 Stirling Highway,

Crawley, WA 6009, Perth, Australia is about 65 times larger than that of Australia. On the one hand, resources per capita in China are much less than those of Australia. On the other hand, both China and Australia are facing similar challenges on their way to further development. Problems occur frequently on the low-productivity and degraded soils in these regions, including nutrient deficiency, soil erosion, degradation and desertification, soil salinization and sodification, inefficient water use, drought and low-temperature stresses. These problems in some parts of China and Australia are becoming more and more severe due to global climate change, particularly in northwest China, such as Xinjiang, and in the Great Sandy Desert of Australia.

Therefore, to preserve soil resources and restore the degraded ecosystems to produce enough food and fiber for an ever-increasing population in a sustainable way is an urgent hot topic both in China and in Australia, especially in the present world facing global warming challenges.

Under such circumstances, initiated by Prof. Hans Lambers, Prof. F. Andrew Smith from Australia and Prof. Yong-Guan Zhu and Prof. Yongchao Liang from China, a successful international workshop on SoilPlant Interactions and Sustainable Agriculture in Arid Environments was held in Shihezi, Xinjiang Uygur autonomous region, China, on July 11-19, 2008. The workshop provided a valuable forum for 120 scientists from Australia, USA, Germany, UK, Japan, Israel, France, Serbia and China to present their work. In total 80 participants presented their abstracts and 
30 participants delivered their oral presentations focusing on the most recent scientific progress in the following areas:

(1) biochemical and microbial processes of nutrient cycling in soil-plant systems,

(2) water transport mechanisms and water management in arid ecosystems,

(3) physiological and molecular mechanisms of plant adaptation to stressed environments, and

(4) nutrient and/or metal bio-availability in agro-ecosystems.

One of the most important issues presented and discussed at the workshop was the roles of using both physiological and molecular approaches in exploring plant adaptation to stressful environments such as nutrient deficiency, water deficit stress, salt stress and low temperature stress. Another most interesting topic is the most recent advances in the roles of microbes in nutrient transformation, availability and cycling and plant growth, particularly of arbuscular mycorrhizas in mobilizing nutrient such as phosphorus, alleviating heavy metals toxicity and enhancing plant performance in stressful environments. Also crop adaptations to salinity and measures to be taken to enhance crop performance under salinity stress were among the topics discussed.

In this special issue, some of the representative peer-reviewed papers covering the above themes are published.

This workshop was organized by Shihezi University and Xinjiang Institute of Ecology and Geography, Chinese Academy of Sciences, and co-supported by the Chinese Association for Science and Technology, National Natural Science Foundation of China, Shihezi University, Xinjiang Institute of Ecology and Geography, Chinese Academy of Sciences, Australian Academy of Sciences, International Copper Association (China branch) and Key Laboratory of Oasis EcoAgriculture, Shihezi University. Thanks are given to all participants and sponsors for their support, and to Plant and Soil for devoting a part of this issue to papers from this workshop. 